\title{
Evaluation of the Demographic and Clinical Data of Psoriasis Patients: A Detailed Analysis of a Big Series
}

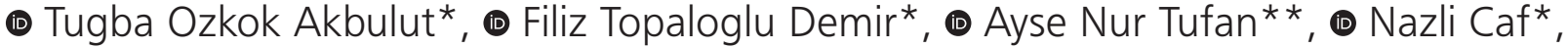 \\ ๑ Baran Cayhan*, ๑ Senay Agirgol*, ๑ Zafer Turkoglu* \\ *University of Health Sciences Turkey, Istanbul Haseki Training and Research Hospital, Clinic of Dermatology, Istanbul, Turkey \\ **University of Health Sciences Turkey, Istanbul Haseki Training and Research Hospital, Clinic of Rheumatology, Istanbul, Turkey
}

\section{Abstract}

\begin{abstract}
Aim: Psoriasis is a chronic disease and requires follow-up settings to manage. The aim of the study is to evaluate the clinical characteristics, disease course, the factors associated with the psoriasis area severity score index (PASI), comorbidities, and treatment of psoriasis in our follow-up psoriasis outpatient clinic.
\end{abstract}

Methods: Clinical data from patients who were followed in the University of Health Sciences Turkey, Haseki Training and Research Hospital psoriasis outpatient clinic between January 2015 and March 2021 were examined. The relationships between age, age of the disease onset, gender, joint involvement, and nail involvement were analyzed.

Results: In total, 618 patients were included in our study (320 males and 298 females). The median age of the patients was 42 (187 ) years. Family history was present in $25.9 \%$ of the patients. The most common clinical type was plaque psoriasis (80.2\%). The median value of the PASI was 8.1 . The disease course of the patients was progressive (46.4\%), remission and exacerbations (37\%), and regressive (16.7\%). Nail involvement and joint involvement were observed in $58.1 \%$ and $24.2 \%$ of the patients, respectively. A significant correlation was found between PASI and joint involvement ( $p=0.009)$. Onycholysis (a type of nail involvement) was a positive predictive indicator for joint involvement $(p=0.004)$. Comorbidity was present in $34.5 \%$ of the patients. Obesity, hypertension, diabetes mellitus, and dyslipidemia were the most common comorbidities. While $19.9 \%$ of the patients received only topical treatment, $80.1 \%$ underwent systemic treatment.

Conclusions: The socio-demographic and enriched clinical data of psoriasis highlight the features that should be considered, especially in follow-up outpatient clinics. Patients showing an early onset of the disease should be investigated for severe involvement, such as the presence of onycholysis in the nail or evidence of joint involvement. The follow-up and treatment of patients with psoriasis are important in terms of comorbidities.

Keywords: Psoriasis, demographic, plaque, joint

\section{Introduction}

Psoriasis is a chronic inflammatory disease that affects $2-3 \%$ of people worldwide (1) and can involve the skin, nails, and joints. The prevailing opinion is that psoriasis is a systemic inflammatory disease that occurs due to concomitant hypertension, diabetes, metabolic syndrome, hyperlipidemia, coronary artery disease, and comorbidities such as depression and anxiety (2).
The current recommendation is that patients with psoriasis should be followed up in outpatient clinics to allow for a multidisciplinary approach. Revealing the clinical and socio-demographic characteristics may help to guide treatment approaches and clinical management (3). Patient data for psoriasis follow-up in outpatient clinics in our country is available in various regions (4-11).

In this study, our aim is to examine the sociodemographic and comprehensive clinical data, including

Address for Correspondence: Tugba Ozkok Akbulut

University of Health Sciences Turkey, Istanbul Haseki Training and Research Hospital, Clinic of Dermatology, Istanbul, Turkey

Phone: +90 5542429026 E-mail: dderm08@hotmail.com ORCID: orcid.org/0000-0001-9995-2543

Received: 14.11.2021 Accepted: 01.01.2022

'Copyright 2022 by The Medical Bulletin of Istanbul Haseki Training and Research Hospital The Medical Bulletin of Haseki published by Galenos Yayinevi. 
disease course, disease onset, and visual analogue scale (VAS)-pruritus, of the patients followed in the psoriasis outpatient clinic of our hospital.

\section{Methods}

The study approval was obtained from the ethics committee of the University of Health Sciences Turkey, Haseki Training and Research Hospital (no: 273, date: 31.10.2019). The follow-up charts of the psoriasis patients admitted to our hospital between January 2015 and March 2021 were retrospectively analyzed. Informed consent was obtained from each patient. Patients with incomplete clinical information were excluded from the study. The patients' data included age, gender, onset age of psoriasis, the type of onset of the disease, disease course, duration of the disease, family history, clinical types, joint involvement, nail involvement, smoking and alcohol use history, concomitant systemic diseases, body mass index (BMI), the psoriasis area and severity index (PASI), VAS-pruritus, VAS-skin pain, and topical and systemic treatments given to the patient. We categorized pruritus and skin pain into three groups using a 0 to $10 \mathrm{~cm}$ VAS: $<5$, mild; 5-7, moderate; and $>7-10$, severe pruritus and skin pain.

\section{Statistical Analysis}

For statistical analysis, SPSS 15.0 for Windows Excel was used for statistical analysis. Descriptive statistics were given as numbers and percentages for categorical variables and numerical variables as the mean, standard deviation, minimum, and maximum. The rates in independent groups were compared using the chi-square test. The statistical significance level of alpha was accepted as $p<0.05$.

\section{Results}

A total of 618 patients attending our psoriasis follow-up outpatient clinic were included in the study. The median age was 42 years [interquartile range (IQR) 28-52.3]; 320 $(51.8 \%)$ were male and $298(48.2 \%)$ were female. The median duration of the disease was 10 years (IQR 3-36). The age of the patients did not differ significantly between the genders $(p>0.05)$. The median age of onset was 22.5 years (IQR 14-40) for women and 27 years (IQR 17-40) for men, and this difference was statistically significant $(p=0.014)$.

Evaluation of the patients by weight and height characteristics revealed a median BMI of $27 \mathrm{~kg} / \mathrm{m}^{2}$ (IQR 23.7-30.4). The median PASI score was 8.1 (IQR 4.2-13.4). The PASI scores were greater than 10 in 246 patients $(41.5 \%)$ and less than 10 in 347 patients (58.5\%). The disease onset of the patients was sudden in 347 (56.2\%) and gradual in 270 (43.8\%). The disease course of the patients was progressive in 286 patients (46.4\%), remission and exacerbations in 228 patients (37\%), and regressive in 103 patients (16.7\%). 73.2\% of the patients complained of pruritus, varying in severity from 3 to 5 , using a VAS (0-10). The median VAS-skin pain was 2 (IQR 1-2) (Table 1).

The smoking rate among the patients was $43.3 \%$, and the alcohol use rate was $7 \%$. The PASI was greater than 10 in $47.4 \%$ of the smoking cases and in $36.7 \%$ of the non-smoking cases, and this difference was statistically significant $(p=0.009)$. No correlation was observed between alcohol consumption and PASI.

Psoriasis history was present in first-degree relatives of $95(15.4 \%)$ patients, in second-degree relatives of 50 $(8.1 \%)$ patients, and in both first- and second-degree relatives of $15(2.4 \%)$ patients. The median age of the disease onset was significantly lower in patients with a family history of psoriasis [20.5 years (IQR 14.3-30.8)] than in those without a family history [27 years (IQR 1742)] ( $p=0.001)$.

A total of 213 patients (34.5\%) had comorbidity in the form of concomitant diseases. Obesity was present in 156 (27.0) patients, hypertension in 107 (17.3\%), diabetes mellitus in $71(11.5 \%)$, dyslipidemia in 67 (10.8\%), thyroid diseases in $37(6 \%)$, and coronary artery diseases in 34 (5.5\%).

The most common of the clinical types among the patients were plaque-type (80.2\%) (Figure 1) and guttate type (23.4\%). The distribution of lesion locations is given in Table 2.

Nail findings were present in 356 (58.1\%) of the patients. The most common nail findings were pitting in $293(47.4 \%)$ patients and onycholysis in 135 (21.8\%). The rate of nail findings in patients with joint findings was statistically significantly higher $[p=0.009$ OR: 1.62 (95\% $\mathrm{Cl}$ 1.09-2.40)]. The rate of incidence of onycholysis among the nail findings was higher in patients with joint findings than in those without joint findings, and the difference was statistically significant ( $p=0.004$ OR: 1.86 95\% Cl 1.22-2.85) (Table 2).

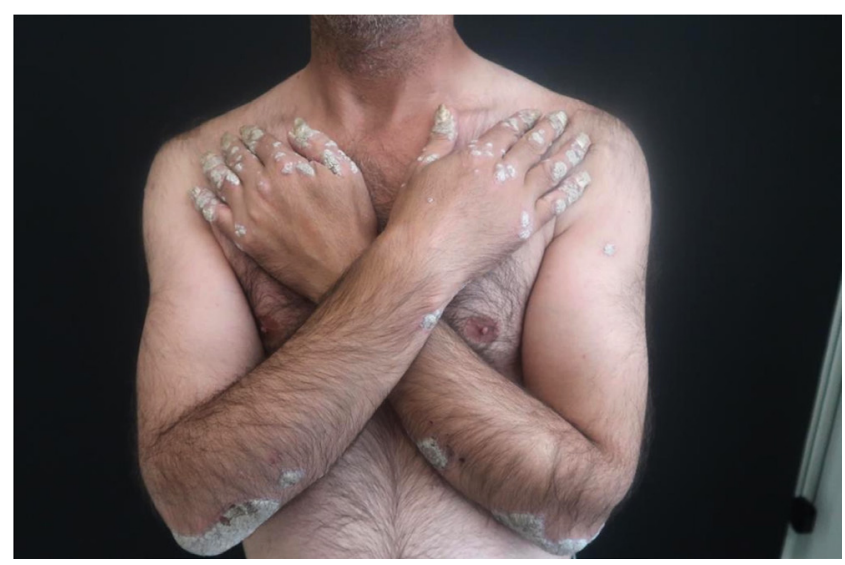

Figure 1. Plaque-type psoriasis 
Arthritis was detected in $24.2 \%$ of the patients (149 patients). The rate of joint involvement was higher in patients with PASI scores greater than 10 (30.1\%)

\begin{tabular}{|c|c|c|}
\hline \multirow{2}{*}{ Sex, n (\%) } & Female & $298(48.2)$ \\
\hline & Male & $320(51.8)$ \\
\hline \multicolumn{2}{|l|}{ Age, years, median (IQR) } & $42(28-52.3)$ \\
\hline \multirow{3}{*}{ Age, years, $\mathrm{n}(\%)$} & $<18$ & $59(9.5)$ \\
\hline & $18-64$ & $510(82.5)$ \\
\hline & $\geq 65$ & $49(7.9)$ \\
\hline \multicolumn{2}{|l|}{ BMI, kg/m², median (IQR) } & $27(23.7-30.4)$ \\
\hline \multirow{4}{*}{ BMI, n (\%) } & $<20 \mathrm{~kg} / \mathrm{m}^{2}$ & $44(7.6)$ \\
\hline & $20-25 \mathrm{~kg} / \mathrm{m}^{2}$ & $163(28.2)$ \\
\hline & $25-30 \mathrm{~kg} / \mathrm{m}^{2}$ & $215(37.2)$ \\
\hline & $\geq 30 \mathrm{~kg} / \mathrm{m}^{2}$ & $156(27.0)$ \\
\hline \multicolumn{2}{|l|}{ DLQI, median (IQR) } & $12(5-19)$ \\
\hline \multicolumn{2}{|l|}{ PASI, median (IQR) } & $8.1(4.2-13.4)$ \\
\hline \multirow{2}{*}{ PASI } & $<10$ & $347(58.5)$ \\
\hline & $\geq 10$ & $246(41.5)$ \\
\hline Pruritus & & $450(73.2)$ \\
\hline \multicolumn{2}{|c|}{ VAS-pruritus, median (IQR) } & $4(3-5)$ \\
\hline \multicolumn{2}{|c|}{ VAS-skin pain, median (IQR) } & $2(1-2)$ \\
\hline \multirow{2}{*}{ Disease onset, n (\%) } & Gradual & $270(43.8)$ \\
\hline & Sudden & $347(56.2)$ \\
\hline \multirow{3}{*}{ Disease course, $n(\%)$} & Progressive & $286(46.4)$ \\
\hline & Regressive & $103(16.7)$ \\
\hline & $\begin{array}{l}\text { Remissions and } \\
\text { exacerbations }\end{array}$ & $228(37.0)$ \\
\hline \multicolumn{2}{|c|}{ Disease onset age, years, median (IQR) } & $25(16-40)$ \\
\hline \multicolumn{2}{|c|}{ Duration of psoriasis, years, median (IQR) } & $10(3-36)$ \\
\hline \multicolumn{2}{|l|}{ Smoker, yes, n (\%) } & $274(43.3)$ \\
\hline $\begin{array}{l}\text { Alcohol insumption, yes, } \\
\mathrm{n}(\%)\end{array}$ & & $43(7.0)$ \\
\hline \multirow{3}{*}{ Family history of psoriasis } & \begin{tabular}{|l|} 
First-degree \\
\end{tabular} & $95(15.4)$ \\
\hline & Second-degree & $50(8.1)$ \\
\hline & Both & $15(2.4)$ \\
\hline \multirow{7}{*}{ Comorbidities, yes, n (\%) } & & $213(34.5)$ \\
\hline & Obesity & $156(27.0)$ \\
\hline & Hypertension & $107(17.3)$ \\
\hline & Diabetes & $71(11.5)$ \\
\hline & $\begin{array}{l}\text { Dyslipidemia/ } \\
\text { hyperlipidemia }\end{array}$ & $67(10.8)$ \\
\hline & Thyroid disease & $37(6)$ \\
\hline & $\begin{array}{l}\text { Coronary artery } \\
\text { disease }\end{array}$ & $34(5.5)$ \\
\hline
\end{tabular}

than in those with PASI scores less than 10 (20.9\%) $(p=0.010)$.

In total, 123 of the patients (19.9\%) were only receiving local treatments, 197 (32\%) were treated with phototherapy, and 425 (68.8\%) were receiving systemic treatments. Methotrexate $(53.1 \%)$ was the most common systemic treatment. The distribution of systemic treatments is given in Table 2 .

\begin{tabular}{|c|c|c|}
\hline \multicolumn{3}{|l|}{ Clinical type, n (\%) } \\
\hline & Plaque & $493(80.2)$ \\
\hline & Guttate & $144(23.4)$ \\
\hline & Palmoplantar & $58(9.4)$ \\
\hline & Inverse & $41(6.7)$ \\
\hline & Generalized pustular & $16(2.6)$ \\
\hline & Localized pustular & $14(2.3)$ \\
\hline & Erythrodermic & $7(1.1)$ \\
\hline \multicolumn{3}{|l|}{ Involvement } \\
\hline \multicolumn{2}{|l|}{ Scalp } & $437(71.1)$ \\
\hline \multicolumn{2}{|l|}{ Dorsum of hand } & $312(50.7)$ \\
\hline \multicolumn{2}{|l|}{ Face } & $206(33.5)$ \\
\hline \multicolumn{2}{|l|}{ Nail } & $356(58.1)$ \\
\hline & Pitting & $293(47.4)$ \\
\hline & Onycholysis & $135(21.8)$ \\
\hline & Subungual hyperkeratosis & $114(18.4)$ \\
\hline & Discoloration & $89(14.4)$ \\
\hline & Oil drop sign & $83(13.4)$ \\
\hline & Splinter hemorrhage & $34(5.5)$ \\
\hline & Leukonychia & $17(2.8)$ \\
\hline & Beau's lines & $11(1.8)$ \\
\hline \multicolumn{2}{|l|}{ Psoriatic arthritis } & $149(24.2)$ \\
\hline \multicolumn{2}{|l|}{ Phototherapy } & $197(32.0)$ \\
\hline \multicolumn{2}{|c|}{ Systemic conventional treatments } & $425(68.8)$ \\
\hline & Methotrexate & $328(53.1)$ \\
\hline & Acitretin & $240(38.8)$ \\
\hline & Cyclosporine & $72(11.7)$ \\
\hline \multicolumn{2}{|l|}{ Biologics } & $127(20.6)$ \\
\hline & Adalimumab & $44(7.1)$ \\
\hline & Ustekinumab & $42(7.0)$ \\
\hline & Etanercept & $33(5.3)$ \\
\hline & Secukinumab & $29(4.7)$ \\
\hline & Ixekizumab & $9(1.5)$ \\
\hline & Infliximab & $8(1.3)$ \\
\hline & Certolizumab & $6(1)$ \\
\hline
\end{tabular}




\section{Discussion}

Psoriasis is a systemic inflammatory disease that occurs in $2 \%$ of the population, with a more common incidence in Europe and America than in East Africa and Asia (3). Its prevalence was $1.18 \%$ in the study by Yaylı et al. (9). Psoriasis has been reported equally frequently in men and women, in general (1); for example, Ferrándiz et al. (12) found a female-male ratio of $1.12 / 1$ in a large patient cohort; Kundakci et al. (4) found a ratio of $1.5 / 1$, and Rifaioglu and Özarmağan (8) found a ratio of $0.95 / 1$. In our study, the female-to-male ratio was $1.07 / 1$, in agreement with the literature.

Psoriasis can occur at any age, with the most common onset in the second and third decades, although it may start at an earlier age in women (1-3). One study conducted in Spain reported the age of onset of psoriasis at 28.2 years in women and 31.8 years in men (12). Topal et al. (10) found an onset of psoriasis at age 27.1 in women and 28.4 in men. In the present study, psoriasis also started at an earlier age in women (22.5 years) than in men (27 years) $(p=0.014)$.

Previous studies have reported a family history of psoriasis in $17.9 \%$ and $44 \%$ of the patients $(13,14)$. The risk of the disease is $63 \%$ in monozygotic twins and $15 \%$ in dizygotic twins (15). A study of 444 patients in our country established a family history of psoriasis in $31.9 \%$ of the patients (16). Family history was reported in $27.9 \%$ of the patients in the study by Aksoy and An (11), and in $24.9 \%$ in the study by Topal et al. (10). Similarly, a family history was present in $25.5 \%$ of the patients in our study. Solmaz et al. (16) determined that the presence of a family history was also associated with an earlier onset of the disease. Similarly, in our study, the disease started earlier in patients with a family history of psoriasis than in those without a family history of psoriasis $(p=0.001)$.

Some patients experience chronic, persistent lesions for many years, while others experience short- or longterm remissions (17). The course of the disease is generally different in patients, and this is unpredictable (14). Similarly, in this study, the disease progressed progressively in almost half of the patients, with remissions and exacerbations in one-third.

Smoking, as this leads to an increase in free radicals that activate the signaling pathways that are important in psoriasis pathogenesis (18). Being a smoker has been identified as an independent risk factor for the development of psoriasis, and smoking habits are observed twice as often in psoriasis patients $(19,20)$. Aksoy and An (11) found a smoking rate in their psoriasis patients of 28.9\%, whereas Rifaioglu and Özarmağan (8) found a rate of $42.3 \%$. In our study, $43.3 \%$ of the patients were smokers. Smoking has also been associated with more severe diseases (20); a study conducted in our country also reported a similar association between smoking and disease severity (21). In agreement with the literature, the severity of the disease in our study was significantly higher in patients with psoriasis who smoked $(p=0.009)$.

The results of studies on the effects of alcohol use on psoriasis have been contradictory $(8,11,22)$. For example, Aksoy and An (11) reported alcohol use in 1.3\% of their psoriasis patients, based on a conservative cohort representation. By contrast, Rifaioglu and Özarmağan (8) found an alcohol use rate of $19.2 \%$. In our study, $7 \%$ of the patients were using alcohol.

Psoriasis is a clinically heterogeneous disease. Plaque psoriasis (23) and lichen planopilaris (24) are the most common clinical types, accounting for $70-80 \%$ of cases. In our study, most patients had the plaque-type. Topal et al. (10) reported the plaque-type in $74 \%$ of their patients, the guttate type in $23.5 \%$, the generalized pustular type in $3 \%$, and the palmoplantar type in $2 \%$. Turan et al. (7) reported the plaque-type in $73.7 \%$ of their patients, the guttate type in $14.5 \%$, the palmoplantar type in $7.6 \%$, the inverse type in $2.8 \%$, and the generalized pustular type in $0.4 \%$. In our study, $80.2 \%$ of the patients had plaque-type lesions, $23.4 \%$ had guttate lesions, $9.4 \%$ had palmoplantar lesions, and $6.7 \%$ had inverse involvement, in conformity with the literature.

Joint involvement has been reported in $4.1-40 \%$ of patients with psoriatic skin lesions $(5,6,22,25,26)$. Turan et al. (7) found joint involvement in $14.5 \%$ of their patients, whereas Gamonal et al. (24) found joint involvement in $24.3 \%$ of their patients. In our study, joint involvement accompanied skin lesions in $24.2 \%$ of the patients, and the presence of joint involvement was verified by rheumatology consultation. Topal et al. (10) reported a higher frequency of joint involvement in patients with PASI scores greater than $10(16.1 \%)$ than in those with PASI scores less than $10(8 \%)(p=0.024)$. In our study, joint involvement was more common in patients with severe disease, as reported in the literature $(p=0.010)$.

Nail involvement has been reported at rates between $16 \%$ and $62.1 \%$ in studies conducted in our country (411). In our study, nail involvement occurred in $58.1 \%$ of the patients, in accordance with the literature. Rifaioglu and Özarmağan (8) found nail involvement in 55.9\% of their patients, whereas Kundakci et al. (4) found a rate of $16 \%$. Ferrándiz et al. (12) reported a significant relationship between nail involvement and joint involvement. In our study, the rate of nail findings was higher in patients with joint findings than in those without joint findings, and the difference was statistically significant [ $p=0.009$ OR: 1.62 (95\% Cl 1.09-2.40)]. In the literature, the most common nail finding was reported as pitting (17.7-20.8\%) and the 
second as onycholysis (15.3\%) $(7,8)$. In our study, $47.4 \%$ of the patients had pitting and $21.8 \%$ had onycholysis, which is in agreement with the literature. The nail finding associated with joint involvement was onycholysis in this study ( $p=0.004$, OR: $1.86,95 \% \mathrm{Cl} 1.22-2.85$ ).

Psoriasis is a systemic inflammatory disease and can be accompanied by several comorbidities, such as hypertension, diabetes, dyslipidemia, coronary artery disease, and metabolic syndrome. A large-scale study conducted in the USA reported that $27 \%$ of patients with psoriasis also had dyslipidemia and $25 \%$ had hypertension (25). Cohen et al. (26) compared 12,502 patients with psoriasis with 24,285 control participants and found hypertension in $38.8 \%(p<0.01)$ of the psoriasis group. Turan et al. (7) reported comorbidities in $30.6 \%$ of their patients, and Aykol et al. (6) found comorbidities in $11.8 \%$ of their patients. In our study, $34.7 \%$ of the patients had a comorbid disease, in agreement with previous studies.

Another striking finding of our study was that $6 \%$ of the patients had comorbid thyroid diseases, which are typically reported at a rate of $3.2 \%$ in the general population (27). A previous study also indicated a high prevalence of thyroid diseases in psoriasis patients, at $9.1 \%$. This situation was especially attributed to the production of IL-17 and IL-23 cytokines, which play an important role in the pathogenesis of both psoriasis and autoimmune thyroiditis (28).

Systemic treatment options for patients who fail to respond adequately to topical or phototherapy treatments can include methotrexate, acitretin, cyclosporine, and biological therapies. Topal et al. indicated that the most common systemic drugs used by patients with psoriasis were acitretin (18\%), methotrexate $(15.7 \%)$, and cyclosporine (5.2\%) (10). Aksoy and An (11) reported that methotrexate $(24.5 \%)$ was the most frequently administered systemic treatment. In our study, 53.3\% of the patients received methotrexate, whereas only $19.7 \%$ received biological treatments. The more frequent preference for methotrexate, one of the conventional agents, in our country may be related to the lack of acitretin or cyclosporine as treatments in the market in 2018-2019.

\section{Study Limitations}

One limitation of our study was its retrospective design, as some data was missing. Another was that, since the comorbidities consisted of file data filled in by reviewing the patient's history, concomitant but not diagnosed diseases could have been missed. Confirming this possibility will require further studies in which patients are prospectively investigated for a wide range of possible accompanying diseases.

The strengths of our study are that it includes the current rates of use of biological treatments, detailed analysis of the relationship between subdistribution of nail findings and joint involvement, and includes extensive file data of psoriasis patients.

\section{Conclusion}

Since psoriasis is a chronic disease, real-life experience data takes on great importance. In this study, we presented the general demographics and clinical characteristics of patients with psoriasis. We observed that thyroid diseases are not uncommon in psoriasis patients. Our results also indicate that psoriasis starts earlier in women and in patients with a family history of psoriasis. The risk of joint involvement appears to be higher in patients with a PASI value of over 10, as well as in patients with nail involvement, especially with signs of onycholysis. It is seen that the course of the disease is progressive in approximately half of the patients, and that it progresses with remissions and exacerbations in more than one third of the patients.

\section{Ethics}

Ethics Committee Approval: The study approval was obtained from the ethics committee of the University of Health Sciences Turkey, Haseki Training and Research Hospital (no: 273, date: 31.10.2019).

Informed Consent: Informed consent was obtained from each patient.

\section{Authorship Contributions}

Concept: T.O.A., S.A., A.N.T., Design: T.O.A., A.N.T., Data Collection or Processing: T.O.A., F.T.D., S.A., N.C., B.C., Analysis or Interpretation: T.O.A., F.T.D., N.C., B.C., Z.T., Literature Research: T.O.A., Z.T., Writing: T.O.A.

Conflict of Interest: No conflict of interest was declared by the authors.

Financial Disclosure: The authors declared that this study received no financial support.

\section{References}

1. Campanati A, Marani A, Martina E, Diotallevi F, Radi G, Offidani A. Psoriasis as an Immune-Mediated and Inflammatory Systemic Disease: From Pathophysiology to Novel Therapeutic Approaches. Biomedicines 2021;9:1511.

2. Parisi R, Symmons DP, Griffiths CE, Ashcroft DM; Identification and Management of Psoriasis and Associated ComorbidiTy (IMPACT) project team. Global epidemiology of psoriasis: a systematic review of incidence and prevalence. J Invest Dermatol 2013;133:377-85.

3. Mehrmal S, Uppal P, Nedley N, Giesey RL, Delost GR. The global, regional, and national burden of psoriasis in 195 countries and territories, 1990 to 2017: A systematic analysis from the Global Burden of Disease Study 2017. J Am Acad Dermatol 2021;84:46-52. 
4. Kundakci N, Türsen U, Babiker MO, Gürgey E. The evaluation of the socio-demographic and clinical features of Turkish psoriasis patients. Int J Dermatol 2002;41:220-4.

5. Tekin NS, Koca R, Altınyazar HC, Çınar S, Muhtar Ş, Aslaner NN. Zonguldak bölgesindeki psoriasis hastalarının sosyodemografik ve klinik özelliklerinin değerlendirilmesi. Turkiye Klinikleri J Dermatol 2005;15:141-6.

6. Aykol C, Mevlitoğlu I, Özdemir M, Ünal M. Konya Yöresindeki Psoriasis Hastalarinin Klinik ve Sosyodemografik Özelliklerinin Degerlendirilmesi. Turk J Dermatol 2011;5:71-4.

7. Turan H, Acer E, Aliağaoğlu C, Uslu E, Albayrak H, Özşahin M. Psoriazisli Hastalarin Klinik ve Sosyodemografik Özelliklerinin Degerlendirilmesi. Turk J Dermatol 2013;7:76-80.

8. Rifaioglu EN, Özarmağan G. Clinical and demographic characteristics of 626 patients with moderate and severe psoriasis. J Clin Anal Med 2014;5:9-14.

9. Yaylı S, Topbaş M, Arıca DA, Tuğcugil S, Çapkın E, Bahadır S. The prevalence of psoriasis in Trabzon. Turkderm-Turk Arch Dermatol Venereol 2016;50:141-4.

10. Topal iO, Değirmentepe E, Cüre K, Kızıltaç U, Hökenek NB, Kocatürk E. Psoriasisli Hastaların Klinik ve Sosyodemografik Özelliklerinin Retrospektif Analizi. Eur Arc Med Res 2017;33:199-205.

11. Aksoy M, An i. Psöriazis tanılı 298 hastanın klinik ve demografik özelliklerinin incelenmesi. Harran Üniversitesi Tıp Fakültesi Dergisi 2019;16:385-8.

12. Ferrándiz C, Pujol RM, García-Patos V, Bordas X, Smandía JA. Psoriasis of early and late onset: a clinical and epidemiologic study from Spain. J Am Acad Dermatol 2002;46:867-73.

13. Kavanaugh A, Papp K, Gottlieb AB, et al. Demography, baseline disease characteristics, and treatment history of psoriasis patients with self-reported psoriatic arthritis enrolled in the PSOLAR registry. BMC Rheumatol 2018;2:29.

14. Özkesici Kurt B, Dönmez L, Nazlım B, et al. Defining the natural course of psoriasis: A single-center cohort study of 100 patients. Turk J Dermatol 2018;12:33-7.

15. Brandrup F, Holm N, Grunnet N, Henningsen K, Hansen HE. Psoriasis in monozygotic twins: variations in expression in individuals with identical genetic constitution. Acta Derm Venereol 1982;62:229-36.

16. Solmaz D, Bakirci S, Kimyon G, et al. Impact of Having Family History of Psoriasis or Psoriatic Arthritis on Psoriatic Disease. Arthritis Care Res (Hoboken) 2020;72:63-8.
17. Osborne JE, Hutchinson PE. Demographic and clinical correlates of extent of psoriasis during stable disease and during flares in chronic plaque psoriasis. $\mathrm{Br} J$ Dermatol 2008;158:721-6.

18. Armstrong AW, Harskamp CT, Dhillon JS, Armstrong EJ. Psoriasis and smoking: a systematic review and meta-analysis. $\mathrm{Br} J$ Dermatol 2014;170:304-14.

19. Herron MD, Hinckley M, Hoffman MS, et al. Impact of obesity and smoking on psoriasis presentation and management. Arch Dermatol 2005;141:1527-34.

20. Lipa K, Zając N, Owczarek W, Ciechanowicz P, Szymaǹska E, Walecka I. Does smoking affect your skin? Postepy Dermatol Alergol 2021;38:371-6.

21.Kayıran N, Korkmaz S, Özgöztaşı O. Impact of smoking on disease severity in patients with plaque type psoriasis. Turkderm-Turk Arch Dermatol Venereol 2015;49(Suppl 1):19-22.

22. Zou L, Lonne-Rahm SB, Helander A, Stokkeland K, Franck J, Nordlind K. Alcohol intake measured by phosphatidylethanol in blood and the lifetime drinking history interview are correlated with the extent of psoriasis. Dermatology 2015;230:375-80.

23. Alpsoy E. Tüm yönleriyle psoriasis. İstanbul: Galenos Yayınevi; 2020.

24. Gamonal SBL, Gamonal ACC, Brandão MAF, Junqueira LA, Assis PM, Raposo NRB. Prevalence of psoriatic arthritis among patients with plaque psoriasis: a Brazilian retrospective study. Sao Paulo Med J 2021;139:476-80.

25. Kimball AB, Guérin $A$, Tsaneva $M$, et al. Economic burden of comorbidities in patients with psoriasis is substantial. J Eur Acad Dermatol Venereol 2011;25:157-63.

26. Cohen AD, Weitzman $D$, Dreiher J. Psoriasis and hypertension: a case-control study. Acta Derm Venereol 2010;90:23-6.

27. Garmendia Madariaga A, Santos Palacios S, Guillén-Grima F, Galofré JC. The incidence and prevalence of thyroid dysfunction in Europe: a meta-analysis. J Clin Endocrinol Metab 2014;99:923-31.

28. Borges AS, Valejo Coelho MM, Brasileiro A. A possible association between psoriasis and thyroid dysfunction. Eur J Dermatol 2018;28:715-6. 